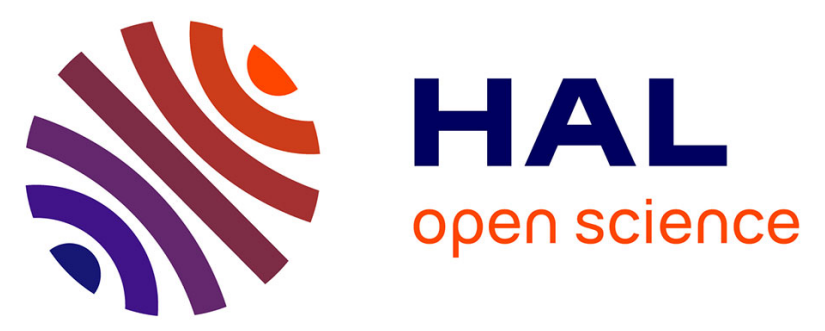

\title{
Health-related quality of life among children with Turner syndrome: controlled cross-sectional study
}

Pascal Amedro, Nabil Tahhan, Héléna Bertet, Claire Jeandel, Sophie Guillaumont, Thibault Mura, Marie-Christine Picot

\section{- To cite this version:}

Pascal Amedro, Nabil Tahhan, Héléna Bertet, Claire Jeandel, Sophie Guillaumont, et al.. Healthrelated quality of life among children with Turner syndrome: controlled cross-sectional study. Journal of Pediatric Endocrinology and Metabolism, 2017, 30 (8), pp.863-868. 10.1515/jpem-2017-0026 . hal-01757618

\section{HAL Id: hal-01757618 \\ https://hal.science/hal-01757618}

Submitted on 11 Dec 2019

HAL is a multi-disciplinary open access archive for the deposit and dissemination of scientific research documents, whether they are published or not. The documents may come from teaching and research institutions in France or abroad, or from public or private research centers.
L'archive ouverte pluridisciplinaire HAL, est destinée au dépôt et à la diffusion de documents scientifiques de niveau recherche, publiés ou non, émanant des établissements d'enseignement et de recherche français ou étrangers, des laboratoires publics ou privés. 


\section{Health-related quality of life among children with Turner syndrome: controlled cross-sectional study}

\begin{abstract}
Background: The aim of the study was to assess healthrelated quality of life (HR-QoL) in children with Turner syndrome in comparison with controls.
\end{abstract}

Methods: We prospectively recruited 16 female girls with Turner syndrome (mean age $15.2 \pm 2.6$ years) and 78 female controls (mean age $12.7 \pm 2.8$ years) in randomly selected schools. We used the PedsQL, a generic HR-QoL questionnaire (self and parents' versions).

Results: Global HR-QoL scores in Turner syndrome were lower than controls for self-reports (respectively, $74.3 \pm 3.0$ vs. $82.8 \pm 1.3, \mathrm{p}=0.01)$ and parents' reports $(62.7 \pm 3.8$ vs. $80.1 \pm 1.7, \mathrm{p}<0.0001)$. In Turner syndrome, self-reported HR-QoL was impaired in school functioning (70.6 \pm 4.0 vs. $80.71 \pm 1.7, \mathrm{p}=0.02)$, social functioning $(78.2 \pm 4.0$ vs. $90.4 \pm 1.8, \mathrm{p}<0.01)$ and physical functioning $(78.5 \pm 3.2$ vs. $87.1 \pm 1.4, p=0.02$ ), but not in emotional functioning. Parents' reported HR-QoL was impaired in all four dimensions.

\footnotetext{
*Corresponding author: Pascal Amedro, MD, PhD, Pediatric and Congenital Cardiology Department, Montpellier University Hospital, 371 Avenue du Doyen Giraud, 34295 Montpellier, France, Phone: +334673366 39, Fax: +33437332129, E-mail: p-amedro@chu-montpellier.fr; Physiology and Experimental Biology of Heart and Muscles Laboratory - PHYMEDEXP, UMR CNRS 9214 - INSERM U1046, University of Montpellier, Montpellier, France; Self-perceived Health Assessment Research Unit, EA3279, Public Health Department, Mediterranean Medical School, Marseille, France. http://orcid.org/0000-0003-3649-0294 Nabil Tahhan: Pediatric and Congenital Cardiology Department, University Hospital, Montpellier, France

Helena Bertet, Thibault Mura and Marie-Christine Picot: Epidemiology and Clinical Research Department, University Hospital, Montpellier, France; and Clinical Investigation Center, INSERM - CIC 1411, University of Montpellier, Montpellier, France Claire Jeandel: Pediatric Endocrinology Unit, University Hospital, Montpellier, France

Sophie Guillaumont: Pediatric and Congenital Cardiology Department, University Hospital, Montpellier, France; and Pediatric Cardiology and Rehabilitation Unit, Saint-Pierre Institute, Palavas-Les-Flots, France
}

Conclusions: HR-QoL was impaired in this cohort of young females with Turner syndrome, as in previously reported adult studies. In addition to medical treatment and routine clinical follow-up, female girls and teenagers with Turner syndrome should also be supported psychologically by social, educational and psychotherapeutic interventions that aim to address their self-esteem and emotional difficulties.

Keywords: health-related quality of life; pediatrics; PedsQL; Turner syndrome.

\section{Introduction}

Turner syndrome is a rare genetic disorder caused by a complete or partial absence of the $\mathrm{X}$ chromosome. In all cases, there is a short stature. Ovarian failure is common but the degree of infertility depends on the chromosomal abnormality. Bone anomalies, lymphedema, deafness, cardiovascular lesions, thyroid and digestive abnormalities are less frequent.

One out of 2500 female neonates are affected. Epidemiological studies carried out in adult populations refer to a diminished overall life expectancy mostly related to cardio-vascular and metabolic disorders [1].

Quality of life (QoL) assessment in chronic diseases is now considered as a major "patient-related outcome". It has been defined as "the overall life satisfaction" [2] but healthcare professionals need a more operational definition, and most clinical trials refer to "health-related quality of life (HR-QoL). Therefore, HR-QoL questionnaires are built with a multidimensional approach embracing at least physical, social, psychological, mental and functional aspects. The validation of HR-QoL questionnaires requires consistent psychometric properties such as validity, reproducibility and sensitivity to change [2-4]. HR-QoL assessment is more often used as a secondary endpoint, especially in cardiovascular clinical trials [5].

On a large cohort of 568 women with Turner syndrome treated by growth hormone during childhood, Carel et al. [6] showed that patients' self-esteem and social adjustement were impacted by comorbidities such as hearing loss and/ 
or heart diseases. When Turner syndrome is diagnosed during childhood, these young patients must cope with this "rare disease" label, impacting their physical appearance, puberty and sexuality. Besides, some of them have to endure significant cardio-vascular lesions such as bicuspid aortic valve, aortic dilatation, coarctation of aorta and arterial hypertension. This leads to additional burdens such as medical therapy and/or heart surgery [7].

In pediatrics, we recently reported that the impact of a cardio-vascular disease on HR-QoL is crucial when physical activity becomes important, usually at the end of elementary school and throughout adolescence [8]. Besides, we have recently pointed out the link between HR-QoL and the actual physical performances among children with congenital heart diseases aged 8-18 years old [9]. However, no such analogy can be made today among children and teenagers with Turner syndrome, with or without cardio-vascular lesion, as HR-QoL data are lacking in this pediatric population.

Our study aimed at assessing the HR-QoL of girls with Turner syndrome aged 8-18 years old in comparison with a contemporary control population using a generic pediatric health-related QoL questionnaire.

\section{Materials and methods}

\section{Study design}

This comparative cross-sectional study was carried out between May 2014 and October 2014 (6 months) in a tertiary care pediatric department (Montpellier University Hospital, France) and in 10 school classes selected in the Languedoc-Roussillon Region, Southern France.

\section{Patients' population}

Girls with Turner syndrome, as defined by the guidelines of the Turner syndrome study group [10], aged 8-18 years were prospectively recruited during their annual pediatric endocrinology or cardiology outpatient visit. Children with recent surgical or catheter cardiac intervention (6 months delay) and hospitalized children were temporarily excluded but could be recruited during their following annual outpatient visit.

\section{Control population}

From the Education Ministry database, 10 school classes (one per level from 3rd grade [elementary school] to 12th grade [high school]) were randomly selected in the same region as patients' population
(Languedoc-Roussillon, Southern France). In the 10 selected school classes, the study was proposed to all children from 8 to 18 years and their parents. The recruitment procedure was the same for each class and common to the one at the hospital.

\section{HR-QoL questionnaires}

Children filled in the PedsQL 4.0 questionnaire, a generic HR-QoL pediatric instrument developed by Varni et al. [11] and reported by Uzark et al. in a large similar comparative HR-QoL study among cardiac children [12]. In both groups, questionnaires were administered under trained study nurse supervision. Depending on the age of the child, we used one of the two versions available: 8-12 years old and 13-18 years old. At the same time, in a separate room, parents filled in the proxy version of the PedsQL, adapted to the age of their child.

The PedsQL generic QoL questionnaire is dedicated to healthy and ill children and adolescents. The 23-item PedsQL generic questionnaire was designed to measure the core dimensions of health as defined by the World Health Organization, as well as role (school) functioning. The four multidimensional scales are: physical functioning (eight items), emotional functioning (five items), social functioning (five items), school functioning (five items). The three summary scores are: total scale score (23 items), physical health summary score (eight items), psychosocial health summary score (15 items). Each item uses a 5-point Likert scale from 0 (never) to 4 (almost always). Items are reversed scored and linearly transformed to a 0-100 scale, higher scores indicating a better QoL. Psychometric properties showed reliability, validity and responsiveness to clinical change over time [13]. The translation and cultural adaptation into French was performed by MAPI Research Institute following the international guidelines [14]. The psychometric properties of the French version of the PedsQL appeared to be acceptable [15].

\section{Formal aspects}

This study complies with the Declaration of Helsinki. It was approved by our Institutional Ethics Committee (South Mediterranean IV) and was registered on ClinicalTrials.gov (number NCT01202916). The Ministry of Education Regional Authority authorized schools' participation. Informed consent was obtained from all parents.

\section{Statistical analysis}

The study population was described with means and standard deviations (SD) or standard errors of the mean (SEM) for quantitative variables and with frequencies and percentage for qualitative variables. Quantitative variables were compared with the parametric Student's t-test when the distribution was Gaussian and with the Mann-Whitney test otherwise. Qualitative variables were compared with the $\chi^{2}$ test or Fisher's exact test.

To compare HR-QoL scores of patients with Turner syndrome and controls, we compared the age-adjusted means ( \pm standard error of the mean, SEM) with an analysis of covariance (ANCOVA).

The two-sided significance level was 0.05. SAS version 9 (SAS Institute, Cary, NC, USA) was used. 
Table 3: Parents-reported PedsQL scores: comparisons between Turner syndrome and controls.

\begin{tabular}{lrrr}
\hline Dimension & $\begin{array}{r}\text { Turner syndrome } \\
\text { Mean (SEM) } \\
(n=16)\end{array}$ & $\begin{array}{r}\text { Controls } \\
\text { Mean (SEM) } \\
(n=73)\end{array}$ & p-Value \\
\hline School & $58.5 \pm 4.8$ & $76.6 \pm 2.1$ & $<0.01$ \\
Social & $58.4 \pm 4.8$ & $86.9 \pm 2.1$ & $<\mathbf{0 . 0 0 0 1}$ \\
Emotion & $54.6 \pm 5.0$ & $70.6 \pm 2.2$ & $<0.01$ \\
Physical & $73.2 \pm 4.6$ & $83.9 \pm 2.0$ & $\mathbf{0 . 0 4}$ \\
Total score & $62.7 \pm 3.8$ & $80.1 \pm 1.7$ & $<\mathbf{0 . 0 0 0 1}$ \\
\hline
\end{tabular}

Mean ( \pm SEM) adjusted on continuous age. Significant $p$-Values $<0.05$ are marked in bold.

is probably multifactorial. Peers and/or teachers might stigmatize children with a chronic disease; parents' overprotection could prevent children from developing some autonomy. Sustained hospital follow-up in the most severe situations (heart surgery, medical treatment) often result in school absenteeism. At school, girls with Turner syndrome might struggle with inhibitory control, being distracted easily, planning and short-term recall as well as working memory [16]. Some of them have an increased likelihood of attention deficit hyperactivity disorder [17]. In a large comparative study, McCauley et al. [16] found that girls with Turner syndrome were less mature than control girls, with weaker social relationships, school performance and self-esteem. This study also described a decline in self-esteem for the girls with Turner syndrome, but not the comparison group, as they moved into early adolescence. School performances are also probably impacted by specific deficits in visual-spatial/perceptual abilities, nonverbal memory function, motor function, executive function that often occur in Turner syndrome $[18,19]$. In line with our results, Boman et al. stated that problems in school accounted for $25 \%$ of the variance in well-being among adult women with Turner syndrome [20]. In Turner syndrome, the non verbal learning disorder usually includes difficulties in adapting to new situations, which could result in inappropriate behavior and lead to some issues with social skills (how to make new friends, how to act in a social environment, etc.). In that context, anxiety and depression may easily develop. Hearing loss in patients with Turner syndrome is another example of situation that might impact both school and social functioning. Conductive and sensorineural hearing losses are frequent in Turner syndrome, representing up to 39\% and $16 \%$, respectively, in a large pediatric cohort [21]. Therefore regular audiological follow-up is extremely important and needs to be performed during childhood. By identifying early stage hearing loss, we might prevent middle ear anatomic sequel and limit HR-QoL impairment among these children.

A third dimension was impaired in our cohort of Turner syndrome patients, but only in the parents' reports: the emotional functioning. Parents usually identify more impact of a chronic disease on their child than the child themselves [8]. Many pediatric studies reported that parents tend to underscore HR-QoL in comparison with the child's own estimation [12, 22-26]. We recently showed in a large cohort of cardiac children that parents were actually more accurate in correlating their child's HR-QoL to the actual severity of the disease [9]. Among teenagers with Turner syndrome, depression, anxiety and shyness are frequent, partly in relation with the premature ovarian failure and the fertility issues $[27,28]$. Some authors tried to evaluate the impact of growth hormone during childhood on HR-QoL in females with Turner syndrome, but results are controversial. Some studies found low HR-QoL scores [29] or high anxiety and depression levels [30]. Others found no difference between patients treated and patients not treated [31]. One study stated that patients' satisfaction with height and breast growth resulted in good HR-QoL scores in social and emotional functioning [32]. According to the recent guidelines, all women with Turner syndrome should be evaluated by an expert as soon as possible in childhood as the vast majority will have their ovarian reserve depleted before adulthood [33]. For the experts, the present challenge is to identify these women as early in life as is possible, so as to allow them to benefit from a variety of existing fertility preservation options. This "challenge" is certainly in the patient's interest, but in the mean time is likely to add more pressure on these children and their family. Therefore, in addition to medical treatment and routine clinical follow-up, girls with Turner syndrome should also be supported psychologically by social, educational and psychotherapeutic interventions that aim to address their self-esteem and emotional difficulties [34].

The physical well-being was also significantly impaired in our cohort of girls with Turner syndrome when compared with the control population, as in a recently reported study [35]. The physical dimension of HR-QoL is usually impaired in children with chronic diseases including motor disabilities, respiratory insufficiency or heart diseases [8]. In our study, one child with Turner syndrome underwent heart surgery for aortic coarctation and four were prescribed cardiac medical drugs but none had a significant hemodynamic impairment. Therefore, once stabilized or healed, the cardiac condition might have taken second place after Turner syndrome itself in terms of HR-QoL. In our recently reported controlled HR-QoL study among a large cohort of 282 children with congenital heart diseases (CHD) vs. 
180 controls, the physical well-being was not impaired for the least severe CHD such as aortic coarctation or bicuspid aortic valve; besides, multivariate analysis showed no impact of any drugs on HR-QoL [8]. In the absence of aortic dilatation, significant aortic valve disease or re-coarctation of aorta after treatment, physical activity and sports are authorized under individual pediatric cardiologist's prescription [36]. High intensity static exercises are however, usually avoided in Turner syndrome. However, studies about physical performance in Turner syndrome remain controversial. Some authors reported a "relatively high level of physical activity" [37], others mentioned "normal force but decreased power" [38], or "limited endurance" [39]. Tancredi et al. [40] showed that the maximal oxygen uptake was lower in adult patients with Turner syndrome than in the controls $(28.4 \pm 4.0$ vs. $35.6 \pm 6.2 \mathrm{~mL} / \mathrm{min} / \mathrm{kg}$; $\mathrm{p}<0.0001)$. We have recently shown that HR-QoL was well correlated to maximal oxygen uptake and anaerobic threshold in pediatric cardiac patients [9]. However, no pediatric data is available in terms of a cardio-pulmonary exercise test in Turner syndrome.

Some patients might suffer from low oxygen uptake, deconditioning or hypertension during effort, which might impact their HR-QoL. Therefore, we plan to perform a complete cardio-pulmonary exercise test in our patients with Turner syndrome in order to evaluate the actual physical performances of these teenagers, before transition to adulthood.

\section{Study limitation}

Most of our patients consented to participate to this HR-QoL study, however, the results are primarily limited by the small size of patients with Turner syndrome. With a larger cohort, a multivariate analysis could help identify explanatory variables (growth hormone, height, fertility, heart lesion, etc.). A multicenter HR-QoL study in Turner syndrome would therefore be very useful.

\section{Conclusions}

HR-QoL was significantly impaired in this cohort of young females with Turner syndrome in comparison to a contemporary control population. School, social and physical functioning were significantly altered for both self and parents' reported HR-QoL, and emotional functioning for parents' reports. In addition to medical treatment and routine clinical follow-up, female children and teenagers with Turner syndrome should also be supported psychologically by social, educational and psychotherapeutic interventions that aim to address their self-esteem and emotional difficulties.

Acknowledgments: We thank Jean-Christophe Azorin, National Ministry of Education, for his collaboration to perform the study in schools. We also thank Cristel Gerl (study nurse), Annie Auer (pediatric specialist nurse), Amandine Marquina (pediatric specialist nurse), Anne Requirand (laboratory technician) and Valerie Macioce (medical writer).

Author contributions: All the authors have accepted responsibility for the entire content of this submitted manuscript and approved submission.

Research funding: Montpellier University Hospital Clinical Research Program funded this work (grant's reference: UF8422).

Employment or leadership: None declared.

Honorarium: None declared.

Competing interests: The funding organization(s) played no role in the study design; in the collection, analysis, and interpretation of data; in the writing of the report; or in the decision to submit the report for publication.

\section{References}

1. Stochholm K, Juul S, Juel K, Naeraa RW, Gravholt CH. Prevalence, incidence, diagnostic delay, and mortality in Turner syndrome. J Clin Endocrinol Metab 2006;91:3897-902.

2. Moons P, Budts W, De Geest S. Critique on the conceptualisation of quality of life: a review and evaluation of different conceptual approaches. Int I Nurs Stud 2006;43:891-901.

3. Bullinger M, Schmidt S, Petersen C, Erhart M, Ravens-Sieberer U. [Methodological challenges and potentials of health-related quality of life evaluation in children with chronic health conditions under medical health care]. Medizinische Klinik 2007;102:734-45.

4. Bullinger M, Ravens-Sieberer U. [General principles, methods and areas of application of quality of life research in children]. Praxis der Kinderpsychologie und Kinderpsychiatrie 1995;44:391-9.

5. Anker SD, Agewall S, Borggrefe M, Calvert M, Jaime Caro J, et al. The importance of patient-reported outcomes: a call for their comprehensive integration in cardiovascular clinical trials. Eur Heart J 2014;35:2001-9.

6. Carel JC, Elie C, Ecosse E, Tauber M, Leger J, et al. Self-esteem and social adjustment in young women with Turner syndrome-influence of pubertal management and sexuality: population-based cohort study. J Clin Endocrinol Metab 2006;91:2972-9.

7. Lopez L, Arheart KL, Colan SD, Stein NS, Lopez-Mitnik G, et al. Turner syndrome is an independent risk factor for aortic dilation in the young. Pediatrics 2008;121:e1622-7.

8. Amedro P, Dorka R, Moniotte S, Guillaumont S, Fraisse A, et al. Quality of life of children with congenital heart diseases: a multicenter controlled cross-sectional study. Pediatr Cardiol 2015;36:1588-601. 
9. Amedro P, Picot MC, Moniotte S, Dorka R, Bertet H, et al. Correlation between cardio-pulmonary exercise test variables and health-related quality of life among children with congenital heart diseases. Int J Cardiol 2015;203:1052-60.

10. Bondy CA, Turner syndrome study G. Care of girls and women with Turner syndrome: a guideline of the Turner syndrome study group. J Clin Endocrinol Metab 2007;92:10-25.

11. Varni JW, Seid M, Rode CA. The PedsQL: measurement model for the pediatric quality of life inventory. Med Care 1999;37:126-39.

12. Uzark K, Jones K, Slusher J, Limbers CA, Burwinkle TM, Varni JW. Quality of life in children with heart disease as perceived by children and parents. Pediatrics 2008;121:e1060-7.

13. Varni JW, Seid M, Kurtin PS. PedsQL 4.0: reliability and validity of the Pediatric Quality of Life Inventory version 4.0 generic core scales in healthy and patient populations. Med Care 2001;39:800-12.

14. Guillemin F, Bombardier C, Beaton D. Cross-cultural adaptation of health-related quality of life measures: literature review and proposed guidelines. J Clin Epidemiol 1993;46:1417-32.

15. Tessier S, Vuillemin A, Lemelle J-L, Briancon S. Psychometric properties of the French Pediatric Quality of Life Inventory Version 4.0 (PedsQL ${ }^{T M} 4.0$ ) generic core scales. Eur Rev Appl Psychol 2009;59:291-300.

16. McCauley E, Ross JL, Kushner H, Cutler G, Jr. Self-esteem and behavior in girls with Turner syndrome. J Dev Behav Pediatr 1995;16:82-8.

17. McCauley E, Feuillan P, Kushner H, Ross JL. Psychosocial development in adolescents with Turner syndrome. J Dev Behav Pediatr 2001;22:360-5.

18. Ross J, Zinn A, McCauley E. Neurodevelopmental and psychosocial aspects of Turner syndrome. Ment Retard Dev Disabil Res Rev 2000;6:135-41.

19. Hong DS, Dunkin B, Reiss AL. Psychosocial functioning and social cognitive processing in girls with Turner syndrome. J Dev Behav Pediatr 2011;32:512-20.

20. Boman UW, Moller A, Albertsson-Wikland K. Psychological aspects of Turner syndrome. J Psychosom Obstet Gynaecol 1998;19:1-18.

21. Bergamaschi R, Bergonzoni C, Mazzanti L, Scarano E, Mencarelli $F$, et al. Hearing loss in Turner syndrome: results of a multicentric study. J Endocrinol Invest 2008;31:779-83.

22. Eiser C, Morse R. Can parents rate their child's health-related quality of life? Results of a systematic review. Qual Life Res 2001;10:347-57.

23. Cremeens J, Eiser C, Blades M. Factors influencing agreement between child self-report and parent proxy-reports on the Pediatric Quality of Life Inventory 4.0 (PedsQL) generic core scales. Health Qual Life Outcomes 2006;4:58.

24. Matziou V, Perdikaris P, Feloni D, Moschovi M, Tsoumakas K, et al. Cancer in childhood: children's and parents' aspects for quality of life. Eur J Oncol Nurs 2008;12:209-16.

25. Marino BS, Tomlinson RS, Drotar D, Claybon ES, Aguirre A, et al. Quality-of-life concerns differ among patients, parents, and medical providers in children and adolescents with congenital and acquired heart disease. Pediatrics 2009;123:e708-15.
26. Upton P, Lawford J, Eiser C. Parent-child agreement across child health-related quality of life instruments: a review of the literature. Qual Life Res 2008;17:895-913.

27. Lesniak-Karpiak K, Mazzocco MM, Ross JL. Behavioral assessment of social anxiety in females with Turner or fragile $X$ syndrome. J Autism Dev Disord 2003;33:55-67.

28. Kilic BG, Ergur AT, Ocal G. Depression, levels of anxiety and self-concept in girls with Turner's syndrome. J Pediatr Endocrinol Metab 2005;18:1111-7.

29. Lasaite L, Lasiene D, Lasas L. Cognition, emotions and quality of life in Lithuanian girls with Turner syndrome after growth hormone therapy discontinuation. J Pediatr Endocrinol Metab 2010;23:443-50.

30. Freriks K, Verhaak CM, Sas TC, Menke LA, Wit JM, et al. Long-term effects of oxandrolone treatment in childhood on neurocognition, quality of life and social-emotional functioning in young adults with Turner syndrome. Horm Behav 2015;69:59-67.

31. Taback SP, Van Vliet G. Health-related quality of life of young adults with Turner syndrome following a long-term randomized controlled trial of recombinant human growth hormone. BMC Pediatr 2011;11:49.

32. Bannink EM, Raat H, Mulder PG, de Muinck Keizer-Schrama SM. Quality of life after growth hormone therapy and induced puberty in women with Turner syndrome. J Pediatr 2006;148:95-101.

33. Oktay K, Bedoschi G, Berkowitz K, Bronson R, Kashani B, et al. Fertility preservation in females with Turner syndrome: a comprehensive review and practical guidelines. J Pediatr Adolesc Gynecol 2016;29:409-16.

34. Siegel PT, Clopper R, Stabler B. The psychological consequences of Turner syndrome and review of the National Cooperative Growth Study psychological substudy. Pediatrics 1998;102:488-91.

35. Nadeem M, Roche EF. Health-related quality of life in Turner syndrome and the influence of key features. J Pediatr Endocrinol Metab 2014;27:283-9.

36. Maron BJ, Chaitman BR, Ackerman MJ, Bayes de Luna A, Corrado D, et al. Recommendations for physical activity and recreational sports participation for young patients with genetic cardiovascular diseases. Circulation 2004;109:2807-16.

37. Sienkiewicz-Dianzenza E, Milde K, Tomaszewski P, Frac M. [Physical activity of girls with Turner's syndrome]. Pediatr Endocrinol Diabetes Metab 2011;17:134-7.

38. Soucek O, Lebl J, Matyskova J, Snajderova M, Kolouskova S, et al. Muscle function in Turner syndrome: normal force but decreased power. Clin Endocrinol (Oxf) 2015;82:248-53.

39. Milde K, Tomaszewski P, Stupnicki R. Physical fitness of schoolgirls with Turner syndrome. Pediatr Exerc Sci 2013;25:27-42.

40. Tancredi G, Versacci P, Pasquino AM, Vittucci AC, Pucarelli I, et al. Cardiopulmonary response to exercise and cardiac assessment in patients with turner syndrome. Am J Cardiol 2011;107:1076-82. 